\title{
Jean Second, CEuvres complètes. Tome V: Itineraria (Carnets de voyage), Correspondance
}

\section{Dario Cecchetti}

\section{(2) OpenEdition}

\section{Journals}

\section{Edizione digitale}

URL: http://journals.openedition.org/studifrancesi/9158

DOI: $10.4000 /$ studifrancesi.9158

ISSN: 2421-5856

\section{Editore}

Rosenberg \& Sellier

\section{Edizione cartacea}

Data di pubblicazione: 1 juin 2008

Paginazione: 173-174

ISSN: 0039-2944

\section{Notizia bibliografica digitale}

Dario Cecchetti, «Jean Second, Euvres complètes. Tome V: Itineraria (Carnets de voyage),

Correspondance», Studi Francesi [Online], 154 (LII | I) | 2008, online dal 30 novembre 2015, consultato il

11 janvier 2021. URL: http://journals.openedition.org/studifrancesi/9158 ; DOI: https://doi.org/

10.4000/studifrancesi.9158

Questo documento è stato generato automaticamente il 11 janvier 2021.

\section{(c) $(1)$}

Studi Francesi è distribuita con Licenza Creative Commons Attribuzione - Non commerciale - Non opere derivate 4.0 Internazionale. 


\title{
Jean Second, Euvres complètes. Tome $\mathrm{V}$ : Itineraria (Carnets de voyage), Correspondance
}

\author{
Dario Cecchetti
}

\section{NOTIZIA}

JEAN SECOND, CEuvres complètes, sous la direction de Roland GUILLOT. Tome V: Itineraria (Carnets de voyage), Correspondance, édition critique établie et annotée, traduction par Roland GUILLOT, Paris, Champion, 2007 («Textes de la Renaissance», 134), pp. 428.

1 La prima edizione degli Opera di Jean Second (Utrecht, 1541), su cui si basa la presente edizione per i primi quattro volumi delle Cuvres complètes, non contiene né gli Itineraria nè le epistolae (di corrispondenza ordinaria). R. Guillot si è servito per i primi due taccuini di viaggio - l'Iter Mechlinia Biturigos (Viaggio da Malines à Bourges) e l'Iter Biturigibus Mechliniam (Viaggio da Bourges a Malines) - dei mss. Vulc. 102 e Vulc. 108 della Biblioteca dell'Università di Leida, copie cinquecentesche, non autografe; per il terzo taccuino - l'Iter Hispanicum, Bruxella in Arragoniam (Viaggio spagnolo, da Bruxelles in Aragona) - della prima edizione (quella di Daniel Heinsius, 1618). Anche per la corrispondenza Guillot ha fatto per lo più ricorso a manoscritti, a volte autografi a volte copie di contemporanei; in assenza del manoscritto ha preso come base l'edizione di P. Bosscha (Leida, 1821). Il primi due Itineraria raccontano un viaggio da Malines a Bourges e ritorno, compiuto per andare a seguire l'insegnamento giuridico di Andrea Alciato, maestro che avrà una profonda influenza (soprattutto nell'orientare alla lettura e traduzione dei classici e nel campo dell'emblematica) su Jean Second. Mentre la relazione del viaggio di andata, svoltosi nel 1532, è opera di Jean Second, quella del viaggio di ritorno, svoltosi nel 1533, è ormai assodato - Guillot ne dà conferma - essere opera del fratello di Second. Il terzo Itinerarium relaziona un viaggio da Bruxelles in Aragona, attraverso Fiandre, Francia e Spagna, compiuto nel 1533, viaggio che permetterà al nostro poeta di diventare segretario dell'arcivescovo di Toledo, e poi 
dello stesso Carlo V. I taccuini di viaggio sono interessanti anzitutto come documento di ambiente e come illustrazione delle condizioni di viaggio dell'epoca, inoltre sono testimonianza del modo con cui s'istauravano rapporti umani e culturali fra intellettuali itineranti nella respubblica litterarum europea. Sono inoltre un preannuncio dell'affermarsi di un genere, fortunatissimo nel Cinquecento, quello del journal de voyage. Infine, sono i soli testi in prosa rimasti di Jean Second, insieme alle dodici lettere qui pubblicate, indirizzate ai fratelli, agli amici Pierre Leclerc et Jean Schorel (il grande pittore Jan van Schoorl, o Scorel). 